14

\title{
Атомный состав и стабильность монослоев Ленгмюра-Блоджетт на основе силоксанового димера кватертиофена на поверхности поликристаллического золота
}

\author{
(C) А.С. Комолов ${ }^{1}$, Э.Ф. Лазнева ${ }^{1}$, Ю.М. Жуков ${ }^{1}$, С.А. Пшеничнюк ${ }^{1,2}$, Е.В. Агина ${ }^{3}$, \\ Д.И. Доминский ${ }^{4}$, Д.С. Анисимов ${ }^{4}$, Д.Ю. Паращук ${ }^{4}$ \\ ${ }^{1}$ Санкт-Петербургский государственный университет, \\ Санкт-Петербург, Россия \\ ${ }^{2}$ Институт ффизики молекул и кристаллов, Уфимский научный центр РАН, \\ Уфра, Россия \\ ${ }^{3}$ Институт синтетических полимерных материалов им. Н.С. Ениколопова РАН, \\ Москва, Россия \\ ${ }^{4}$ Международный учебно-научный лазерный центр, \\ Физический факультет Московского государственного университета им. М.В. Ломоносова, \\ Москва, Россия \\ E-mail: a.komolov@spbu.ru
}

(Поступила в Редакцию 18 апреля 2017 г.

В окончательной редакции 11 мая 2017 г.)

Исследован атомный состав монослоев на основе силоксанового димера кватертиофена, нанесенных методом Ленгмюра-Блоджетт на поверхность диоксида кремния, частично покрытую пленкой золота, и стабильность этих монослоев при обработке поверхности путем бомбардировки ионами $\mathrm{Ar}^{+}$. Экспериментальные результаты по химическому составу серии исследованных поверхностей получены методом рентгеновской фотоэлектронной спектроскопии (XPS) путем регистрации XPS-спектров $\mathrm{C}_{1 s}, \mathrm{O}_{1 s}, \mathrm{~S}_{2 p}$ и $\mathrm{Au}_{4 f}$ остовных уровней. Относительная концентрация атомов $\mathrm{Au}, \mathrm{Si}$ и атомов подложки в составе приготовленной ex situ исследованной поверхности была определена в пределах $10-15 \%$, что говорит о том, что монослои Ленгмюра-Блоджетт на основе силоксанового димера кватертиофена формируют в значительной степени сплошное покрытие. До проведения обработки исследованной поверхности путем бомбардировки ионами $\mathrm{Ar}^{+}$, углерод- и кислород-содержащие поверхностные адсорбаты вносили существенный вклад в результаты XPS измерений. Очистка поверхности ионами $\mathrm{Ar}^{+}$с энергией $3 \mathrm{keV}$ при значениях электрического тока через образец $\sim 1 \mu \mathrm{A}$ в несколько этапов по $30 \mathrm{~s}$ привела к стравливанию поверхностных адсорбатов, а затем и самих пленнок Ленгмюр-Блоджетт пленок силоксанового димера кватертиофена.

Исследования по фотоэлектронной спектроскопии выполнены при финансовой поддержке РФФИ (16-33-50252-мол-нр, 15-29-05786). Исследования по нанесению монослоев Ленгмюра-Блоджетт и их характеризации выполнены за счет гранта Российского научного фонда (проект № 15-12-30031). В работе использовали оборудование научного парка СПбГУ „Физические методы исследования поверхности“.

DOI: $10.21883 /$ FTT.2017.12.45249.132

\section{1. Введение}

Структурные и электронные свойства ультратонких пленок на основе молекул олиготиофенов представляют значительный интерес в связи с возможностью их использования в устройствах органической электроники [1-3]. Пленочные материалы на основе политиофенов и олиготиофенов обладают относительно высокой подвижностью носителей заряда и вместе с тем демонстрируют высокую термическую и термоокислительную стабильность $[1,4]$. При этом в органических полевых транзисторах (ОПТ) транспорт носителей заряда происходит в слое толщиной в несколько нанометров вблизи границы органического полупроводника и подзатворного диэлектрика [2]. Таким образом, органического полупроводникового слоя толщиной в 1-2 молекулы на поверхности подложки достаточно для формирования проводящего канала ОПТ. Одним из наиболее перспективных методов создания поверхностных структур на основе олиготиофенов является метод самосборки из раствора, который позволяет получать кристаллические монослои с относительно высокой подвижностью носителей заряда (self-assembled monolayers) [2-5]. Однако самосборка монослоя из раствора - длительный процесс, который может занимать десятки часов до достижения полного покрытия подложки, поэтому его масштабирование затруднительно. Кроме того, самосборка из раствора возможна только для молекул, имеющих в своем составе реакционноспособные группы (например, хлорсилильные), поэтому такие молекулы нестабильны в условиях обычной атмосферы и требуют использования инертной среды при любых технологи- 


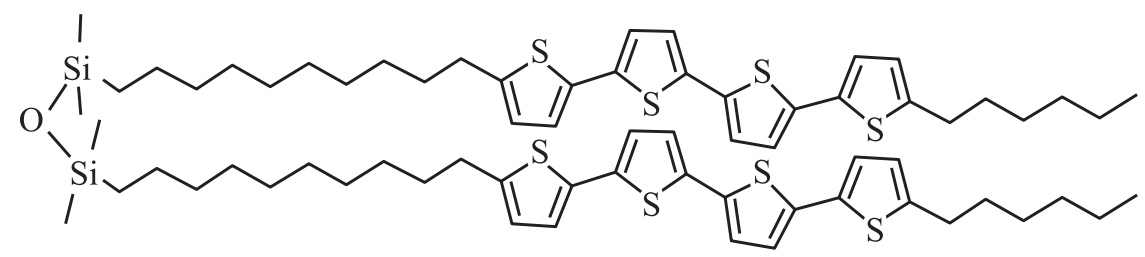

Pис. 1. Структурная формула силоксанового димера кватертиофена (D2-Und-4T-Hex) в сложенной конформации.

ческих процессах. Метод Ленгмюра-Блоджетт (ЛБ) простой и быстрый способ нанесения органических полупроводниковых покрытий с возможностью контроля структуры и морфологии получаемого покрытия, а также степени заполнения им подложки при помощи таких методов, как микроскопия Брюстера, поляризационнооптическая и атомно-силовая микроскопия $[4,6]$. В отличие от метода самосборки из раствора метод ЛБ позволяет получать полупроводниковые монослои на основе химически инертных органических полупроводников, не содержащих реакционноспособных групп, в частности на основе силоксановых димеров $[4,7,8]$. Присутствие в составе молекулы силоксанового фрагмента обеспечивает амфифильность молекулы, достаточную для формирования ленгмюровского слоя на поверхности воды за счет образования водородных связей между атомами кислорода и молекулами воды субфазы.

ЛБ монослои силоксанового димера кватертиофена (рис. 1) были получены и исследованы нами ранее в качестве активного полупроводникового монослоя в ОПТ [4]. Образцы таких устройств на основе силоксанового димера кватертиофена продемонстрировали долговременную стабильность и воспроизводимость электрофизических характеристик в атмосферных лабораторных условиях. Подвижность носителей заряда дырочного типа достигала в них $3 \cdot 10^{-3} \mathrm{~cm}^{2} /(\mathrm{V} \cdot \mathrm{s})$, что не уступает аналогичным характеристикам ОПТ на основе неупорядоченных тонкопленочных органических и композитных материалов [7-10]. В сопряженных органических материалах возможно достичь и на 1-2 порядка бо́льших значений подвижности носителей заряда, однако это в большей степени относится к материалам, термически осажденным в вакууме и демонстрирующим кристаллическую упорядоченность [11]. Методы электронной спектроскопии позволяют непосредственно установить атомный состав и электронную структуру поверхностей, модифицированных тонкими и сверхтонкими органическими покрытиями [12-16]. Вместе с этим электронно-спектроскопические методы дают возможность оценить степень загрязнения органических пленок углероди кислородсодержащими адсорбатами из атмосферы, а также характеристики стабильности органических покрытий при нагреве, воздействии электронным или ионным пучком [17-20]. В настоящей работе приведены результаты исследования атомного состава монослоев Ленгмюра-Блоджетт на основе силоксанового димера кватертиофена на поверхности термически напыленно- го золота и диоксида кремния методом рентгеновской фотоэлектронной спектроскопии (XPS). Приводятся результаты по изучению стабильности исследованных поверхностей при обработке путем ионной бомбардировки.

\section{2. Эксперимент}

Монослои Ленгмюра-Блоджетт силоксанового димера кватертиофена (LB-D2-Und-4T-Hex, рис. 1) были получены по методике [4]. Структура и морфология ЛБ монослоя LB-D2-Und-4T-Нех была установлена ранее с помощью атомно-силовой микроскопии, рентгеновского отражения и рентгеновской дифракции при скользящем угле падения. Степень заполнения подложки монослоем близка к 100\%, при этом химических связей полупроводящий монослой с подложкой не образует. Что касается ориентации молекул в сформированном ЛБ монослое, то молекула димера находится в сложенной конформации, повернута силоксановой группой к подложке, при этом ось олиготиофеновых фрагментов практически перпендикулярна плоскости подложки [4]. Для приготовления ЛБ монослоя раствор димера в толуоле с концентрацией $0.33 \mathrm{mg} / \mathrm{ml}$ капали на поверхность воды ленгмюровской ванны, образовавшийся слой сжимали при помощи барьеров. Перенос на подложку осуществляли методом вертикального переноса (ЛБ) при постоянном поверхностном давлении $35 \mathrm{mN} / \mathrm{m}$, скорость движения подложки $12 \mathrm{~mm} / \mathrm{min}$. Толщина монослойного покрытия LB-D2-Und-4T-Hex была оценена как 3.5-4.0 nm, что хорошо согласуется с половиной расчетной длины молекулы димера в выпрямленной конформации. В качестве подложки для нанесения пленок использовали термически осажденный слой золота толщиной $\sim 100 \mathrm{~nm}$. При конструировании ОПТ такой слой золота играет роль стокового или истокового электрода. Слой золота был нанесен на поверхность пластины $\left(\mathrm{SiO}_{2}\right) n-\mathrm{Si}$ со специально выращенным слоем диоксида кремния толщиной $200 \mathrm{~nm}$. Атомный состав поверхности $\left(\mathrm{SiO}_{2}\right) n-\mathrm{Si}$ был установлен при помощи рентгеновской фотоэлектронной спектроскопии (XPS) и оказался близок к стехиометрическому.

Приготовленный образец был помещен в сверхвысоковакуумные условия для проведения XPS исследований. XPS измерения были проведены на комплексном фотоэлектронном спектрометре Escalab 250Xi (Thermo Fisher Scientific Inc.) с энергией фотонов Al $K_{\alpha}=1486 \mathrm{eV}$. 
Исследования проводили в условиях сверхвысокого вакуума $\sim 10^{-7} \mathrm{~Pa}$ при комнатной температуре, при использовании системы компенсации заряда парциальное давление аргона в аналитической камере составляло $10^{-5} \mathrm{~Pa}$. Обзорные спектры и спектры остовных уровней были записаны при энергии пропускания анализатора 100 и $20 \mathrm{eV}$ соответственно. Рабочие параметры рентгеновской трубки: напряжение на аноде $14.8 \mathrm{keV}$, ток эмиссии $6 \mathrm{~mA}$, размер пятна $650 \mu \mathrm{m}$. дающий пучок фотонов был сфокусирован в области нанесенного на $\left(\mathrm{SiO}_{2}\right) n-\mathrm{Si}$ поверхность $\mathrm{Au}$ электрода. Однако из-за малой площади $\mathrm{Au}$ электродов область анализа захватывала частично и участки поверхности $\left(\mathrm{SiO}_{2}\right) n-\mathrm{Si}$, не покрытые золотом. При анализе измеренных XPS-спектров использовали библиотеку стандартных XPS-спектров [21] и библиотеку производителя оборудования (Thermo Fisher Scientific Inc.), включающую атомные факторы чувствительности регистрации сигнала.

\section{3. Результаты и обсуждение}

Обзорный XPS-спектр поверхности $\mathrm{Si} / \mathrm{SiO}_{2} / \mathrm{Au} / \mathrm{LB}-$ D2-Und-4T-Hex, приготовленной ex situ, представлен на рис. 2. В нем отчетливо наблюдаются максимумы атомных компонент $\mathrm{C}_{1 s}(284.5 \mathrm{eV}), \mathrm{O}_{1 s}(532.4 \mathrm{eV}), \mathrm{S}_{2 p}$ $(163.3 \mathrm{eV}), \mathrm{Au}_{4 f}(83.4 \mathrm{eV})$ и $\mathrm{Si}_{2 s}(154.4 \mathrm{eV})$. С учетом относительных интенсивностей этих XPS максимумов и факторов чувствительности их регистрации [21] относительные концентрации этих пяти атомных компонент составили $\sim 66,18,5,10$ и 15\% соответственно. Полученные относительные концентрации атомов $\mathrm{Au}$ и $\mathrm{Si}$, характерные для материала подложки, свидетельствуют в пользу того, что степень недозаполнения осажденных на подложку монослоев LB-D2-Und-4T-Hex не превышала $25 \%$ в составе исследованной поверхности. Действительно, согласно структурной формуле молекулы D2-Und-4T-Hex (рис. 1), толщина осажденного на подложку монослоя LB-D2-Und-4T-Hex $\sim 4 \mathrm{~nm}$, что несколько меньше глубины XPS анализа при энергиях вторичных электронов, соответствующих максимумам $\mathrm{Au}_{4 f}$ и $\mathrm{Si}_{2 s}[20,22]$. При этом с учетом того, что в составе молекулы D2-Und-4T-Hех присутствует всего один атом кислорода, наличие максимума $\mathrm{O}_{1 s}$ (рис. 2) следует связывать с сигналом, исходящим от $\mathrm{SiO}_{2}$ подложки, и с сигналом кислородсодержащих поверхностных адсорбатов.

Для более детального анализа рассмотрим XPS спектры, измеренные в области максимумов основных атомных компонент исследованных монослоев LB-D2Und-4T-Hex $\mathrm{C}_{1 s}$ и $\mathrm{S}_{2 p}$ (рис. 3, кривые 1). Максимум $\mathrm{C}_{1 s}$ расположен при энергии связи $285 \mathrm{eV}$ (рис. $3, a$ ), что хорошо соответствует литературным данным по энергии связи атома углерода в тиофене или в составе алифатических соединений [22-24]. Максимум $\mathrm{S}_{2 p}$ (рис. 3,b) расположен при энергии связи $164 \mathrm{eV}$, что характерно для молекул тиофена $[22,23]$. С учетом

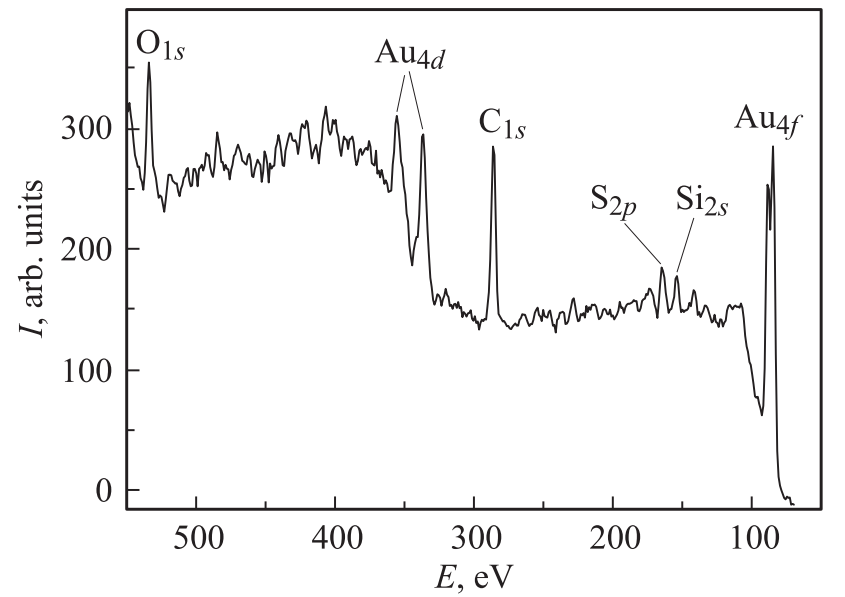

Рис. 2. Обзорный рентгеновский фотоэлектронный спектр (XPS) ex situ приготовленной поверхности $\mathrm{Si} / \mathrm{SiO}_{2} / \mathrm{Au} / \mathrm{LB}-$ D2-Und-4T-Hex без предварительной обработки. Подписаны максимумы основных атомных компонент.

табличных значений чувствительности регистрации XPS сигнала [21] при регистрации максимумов $\mathrm{C}_{1 s}$ и $\mathrm{S}_{2 p}$ примерное отношение концентраций атомов $\mathrm{C}$ и $\mathrm{S}$ без предварительной обработки поверхности образца составило 10:1. Как было показано ранее [10,20,24,25], следует считать, что при приготовлении органических пленок ex situ $\sim 10-20 \%$ измеряемой интенсивности $\mathrm{C}_{1 s}$ максимума также обусловлено поверхностно адсорбированными примесями. Таким образом, за вычетом влияния поверхностно адсорбированных атомов С измеренное соотношение атомных концентраций атомов С и $\mathrm{S}$ в составе слоя LB-D2-Und-4T-Hех можно оценить как $8: 1$. Это достаточно хорошо соответствует химической формуле молекул силоксанового димера кватертиофена в составе исследованного слоя (рис. 1).

Очистку образца проводили методом бомбардировки ионами $\mathrm{Ar}^{+}$с энергией $3 \mathrm{keV}$, что создавало ток через образец $\sim 1 \mu \mathrm{A}$. После проведения первого и второго циклов очистки длительностью $30 \mathrm{~s}$ каждый обнаружено значительное снижение интенсивности $\mathrm{C}_{1 s}$ и $\mathrm{S}_{2 p}$ XPS максимумов (рис. 3, кривые 1-3). Так, после $30 \mathrm{~s}$ очистки поверхности интенсивность $\mathrm{C}_{1 s}$ и $\mathrm{S}_{2 p}$ XPS максимумов снизилась примерно в 5 раз, а после суммарных $60 \mathrm{~s}$ очистки интенсивность $\mathrm{C}_{1 s}$ и $\mathrm{S}_{2 p}$ XPS максимумов снизилась на порядок (рис. 3). Такое уменьшение интенсивности максимумов, характерных для монослоя LB-D2-Und-4T-Hex, говорит о практически полном его удалении с поверхности в результате проведенной бомбардировки ионами $\mathrm{Ar}^{+}$суммарной длительностью $60 \mathrm{~s}$. Энергетическое положение $\mathrm{C}_{1 s}$ и $\mathrm{S}_{2 p}$ XPS максимумов в процессе ионной очистки практически не изменялось (рис. 3). Это свидетельствует о том, что зарядовое состояние атомов $\mathrm{C}$ и $\mathrm{S}$ практически не изменялось в процессе уменьшения средней толщины покрытия LB-D2-Und-4T-Hex, что является показателем однородности пленки LB-D2-Und-4T-Hex. 

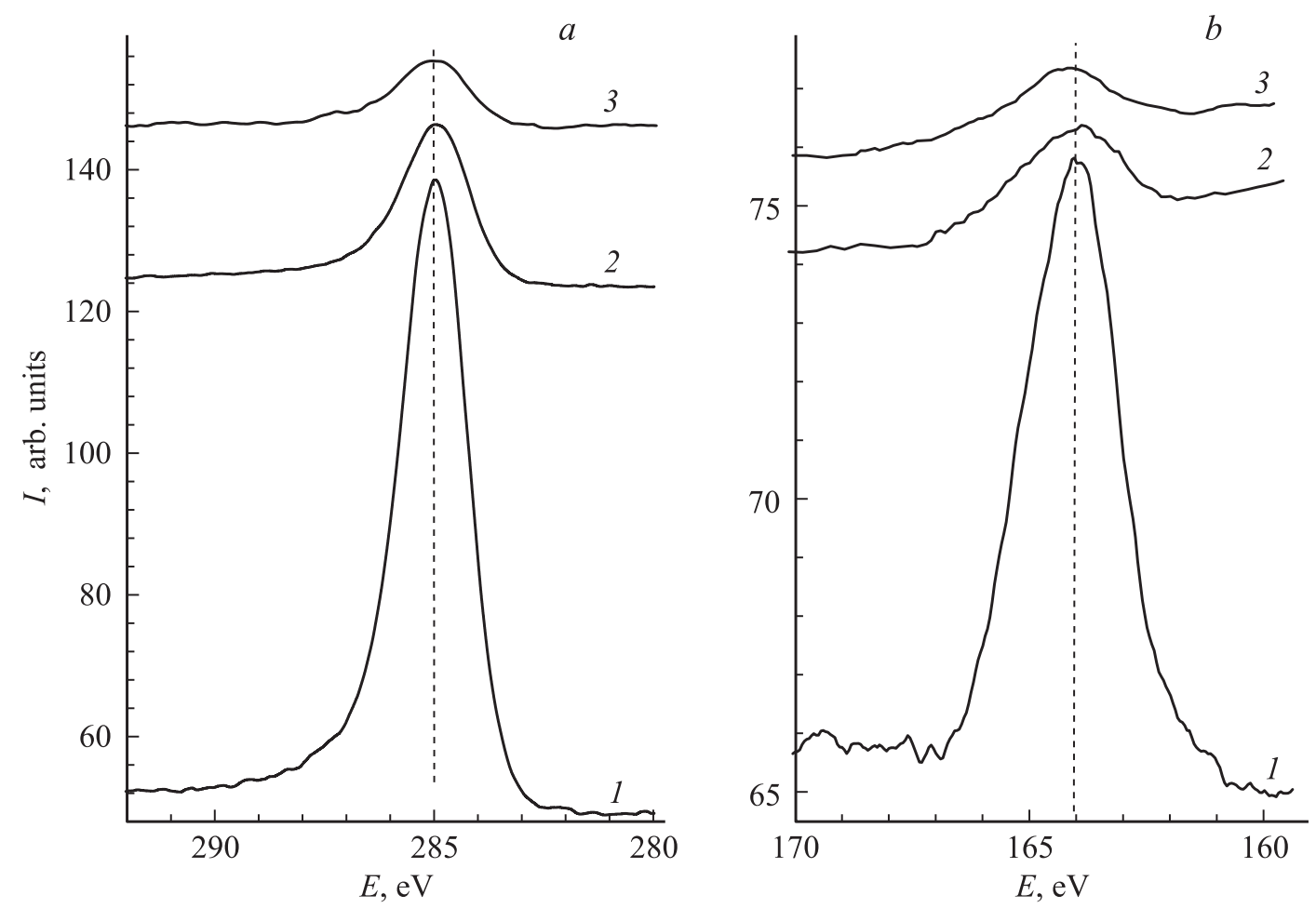

Рис. 3. Рентгеновские фотоэлектронные спектры (XPS) в области максимумов атомных компонент исследованных пленок $\mathrm{LB}-\mathrm{D} 2-\mathrm{Und}-4 \mathrm{~T}-\mathrm{Hex}, \mathrm{C}_{1 s}(a)$ и $\mathrm{S}_{2 p}(b)$. Кривые 1 - без предварительной обработки, кривые 2 - после $30 \mathrm{~s}$ обработки, кривые 3 - после $60 \mathrm{~s}$ обработки ионами $\mathrm{Ar}^{+}$с энергией $3 \mathrm{keV}$.
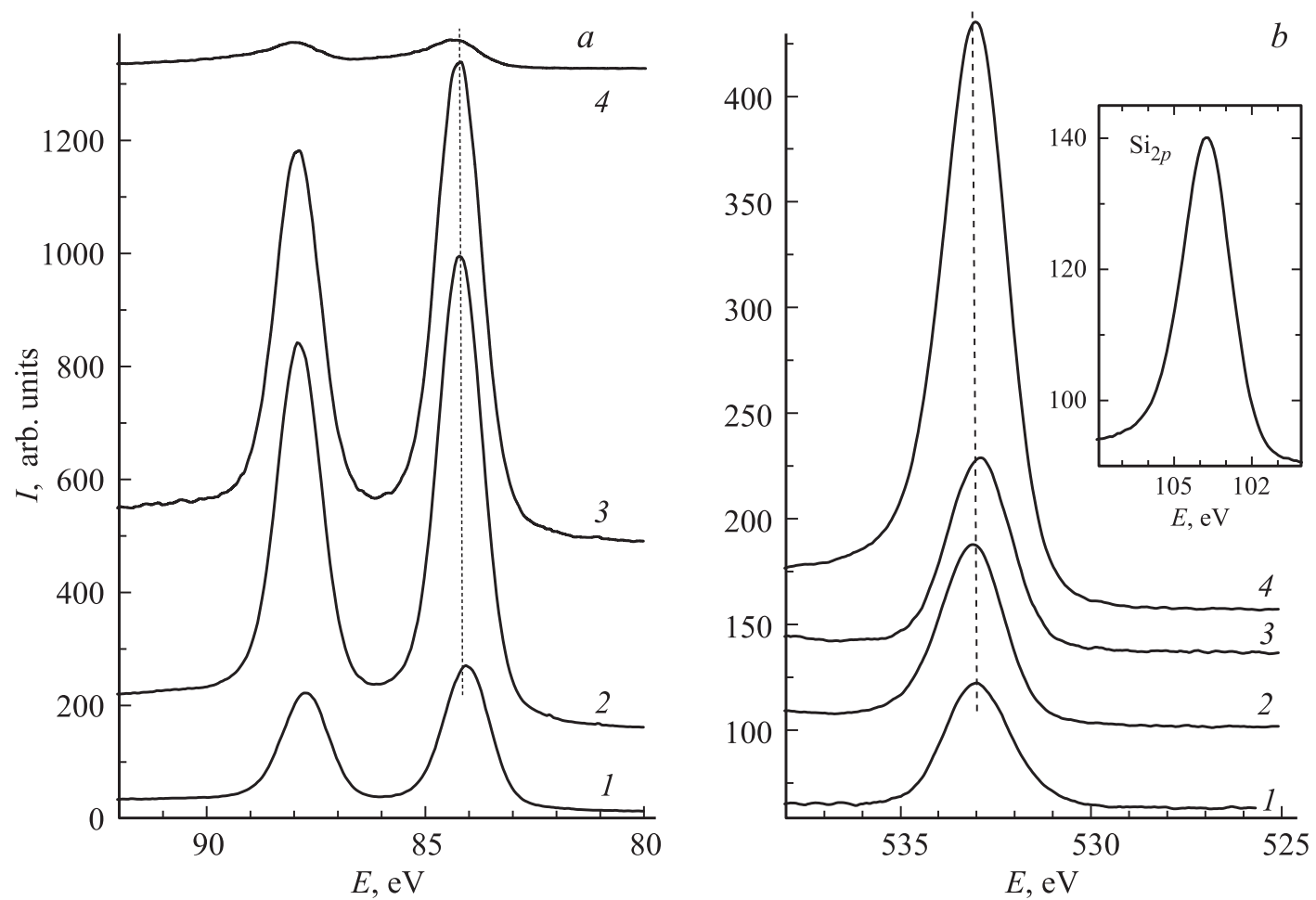

Рис. 4. Рентгеновские фотоэлектронные спектры (XPS) в области максимумов атомных компонент подложки, Аu $4 f(a)$ и $\mathrm{O}_{1 s}(b)$. Кривые 1 - без предварительной обработки, кривые 2 - после $30 \mathrm{~s}$ обработки, кривые 3 - после $60 \mathrm{~s}$ обработки и кривые 4 - после $180 \mathrm{~s}$ обработки ионами $\mathrm{Ar}^{+}$с энергией $3 \mathrm{keV}$. На вставке изображен максимум $\mathrm{Si}_{2 p}$, измеренный после $180 \mathrm{~s}$ обработки поверхности ионами $\mathrm{Ar}^{+}$. 
Как упоминалось ранее при обсуждении рис. 2, ввиду достаточно малой толщины монослоя LB-D2-Und$4 \mathrm{~T}-\mathrm{Hex}$, не превышающей $4 \mathrm{~nm}$, либо ввиду неполного заполнения подложки монослоем в XPS-спектре исследованной поверхности были обнаружены максимумы, характерные для атомных компонент подложки, оксида кремния и напыленного на оксид Аu контакта. Согласно литературным данным, при формирования монослоя методом ЛБ следует ожидать формирования сплошного непористого покрытия $[1,4,26]$, а глубина XPS анализа при энергиях вторичных электронов $>600 \mathrm{eV}$ превосходит толщину исследованного LB-D2-Und-4T-Hex монослоя. Поэтому XPS максимумы атомных компонент подложки, золота, оксида кремния являются характерными при XPS измерениях на исследованных образцах. $\mathrm{Au}_{4 f}$ и $\mathrm{O}_{1 s}$ XPS-спектры исследованных поверхностей, измеренные до проведения ионной очистки, приведены на рис. 4, кривые 1. Максимум $\mathrm{Au}_{4 f}$ представлен дублетом при 84 и $87.5 \mathrm{eV}$ (рис. 4, $a$ ). Пик $\mathrm{O}_{1 s}$ имеет вершину в области $533 \mathrm{eV}$, что соответствует энергии связи атома кислорода в составе $\mathrm{SiO}_{2}[21,22]$. Наличие максимумов $\mathrm{Au}_{4 f}$ и $\mathrm{O}_{1 s}$ в спектрах исследованной структуры одновременно говорит о том, что тестирующий рентгеновский пучок захватывал одновременно и область $\mathrm{Au}$ электрода, и область, не покрытую $\mathrm{Au}$ электродом.

В процессе обработки поверхности методом бомбардировки ионами $\mathrm{Ar}^{+}$с энергией $3 \mathrm{keV}$ обнаружены значительные изменения интенсивности $\mathrm{Au}_{4 f}$ и $\mathrm{O}_{1 s}$ XPS максимумов (рис. 4, кривые 2-4). Так, после $30 \mathrm{~s}$ очистки поверхности интенсивность $\mathrm{Au}_{4}$ максимума увеличилась приблизительно в три раза и сохраняла свое значение после следующего цикла очистки длительностью $30 \mathrm{~s}$. Увеличение интенсивности $\mathrm{Au}_{4 f} \mathrm{XPS}$ максимума указывает на то, что за два цикла ионной очистки произошло удаление с поверхности монослоя LB-D2-Und-4T-Hex, как обсуждалось выше при анализе результатов на рис. 3. Вместе с увеличением интенсивности $\mathrm{Au}_{4}$ XPS максимума наблюдалось увеличение интенсивности и максимума $\mathrm{O}_{1 s}$, исходящего от подложки (рис. $4, b$, кривые 2,3 ). При продолжении ионной очистки поверхности в течение $120 \mathrm{~s}$ было обнаружено резкое уменьшение интенсивности $\mathrm{Au}_{4}$ XPS максимума примерно в 20 раз (рис. 4, $a$, кривая 4), что говорит о том, что в результате такой обработки $\mathrm{Au}$ электрод был удален с поверхности. В то же время в результате суммарной $180 \mathrm{~s}$ ионной очистки исследованной поверхности произошло увеличение интенсивности $\mathrm{O}_{1 s}$ XPS максимума (рис. 4, $b$, кривые 1-4) в 3-4 раза. На вставке к рис. 4, $b$ приведен $\mathrm{Si}_{2 p}$ XPS максимум для поверхности, подвергнутой ионной обработке в течение $180 \mathrm{~s}$. $\mathrm{Si}_{2 p}$ максимум расположен при энергии $103.5 \mathrm{eV}$, что характерно для атомов кремния в составе $\mathrm{SiO}_{2}$. С учетом факторов чувствительности регистрации максимумов $\mathrm{Si}_{2 p}$ и $\mathrm{O}_{1 s}$ [22] и интенсивностей этих максимумов в результате ионной обработки (рис. $4, b$ ) было установлено, что атомный состав поверхности $\mathrm{SiO}_{2}$ был близок к стехиометрическому.

\section{4. Выводы}

Путем регистрации рентгеновских фотоэлектронных спектров (XPS) $\mathrm{C}_{1 s}, \mathrm{O}_{1 s}, \mathrm{~S}_{2 p}$ и $\mathrm{Au}_{4 f}$ остовных уровней экспериментально установлено, что химический состав ЛБ монослоев силоксанового димера кватертиофена (LB-D2-Und-4T-Hex), нанесенных на поверхность поликристаллического золота и диоксида кремния методом Ленгмюра-Блоджетт, хорошо соответствует химической формуле молекул силоксанового димера кватертиофена. Обработка исследованной поверхности ионами $\mathrm{Ar}^{+}$с энергией $3 \mathrm{keV}$ при пропускании через образец электрического тока $\sim 1 \mu \mathrm{A}$ в $1-2$ этапа по 30 s привела к стравливанию поверхностных адсорбатов, а затем и самих пленок Ленгмюр-Блоджетт пленок силоксанового димера кватертиофена.

Авторы благодарят О.В. Борщева и С.А. Пономаренко за предоставление силоксанового димера D2-Und4T-Нех для исследований.

\section{Список литературы}

[1] Q. Xia, M. Burkhardt, M. Halik. Org. Electr. 9, 1061 (2008).

[2] M. Mottaghi, P. Lang, F. Rodriguez, A. Rumyantseva, A. Yassar, G. Horowitz, S. Lenfant, D. Tondelier, D. Vuillaume. Adv. Funct. Mater. 17, 597 (2007).

[3] D.V. Anokhin, M. Defaux, A. Mourran, M. Moeller, Y.N. Luponosov, O.V. Borshchev, A.V. Bakirov, M.A. Shcherbina, S.N. Chvalun, T. Meyer-Friedrichsen, A. Elschner, S. Kirchmeyer, S.A. Ponomarenko, D.A. Ivanov. J. Phys. Chem. C 116, 43, 22727 (2012).

[4] A.S. Sizov, D.S. Anisimov, E.V. Agina, O.V. Borshchev, A.V. Bakirov, M. A. Shcherbina, S. Grigorian, V.V. Bruevich, S.N. Chvalun, D.Yu. Paraschuk, S.A. Ponomarenko. Langmuir 30, 50, 15327 (2014).

[5] О.В. Борщев, С.А. Пономаренко. Высокомол. соед. С 56, 1,33 (2014).

[6] E.V. Agina, I.A. Usov, O.V. Borshchev, J. Wang, A. Mourran, M.A. Shcherbina, A.V. Bakirov, S. Grigorian, M. Moller, S.N. Chvalun, S.A. Ponomarenko. Langmuir 28, 46, 16186 (2012).

[7] E.V. Agina, A.S. Sizov, D.S. Anisimov, A.A. Trul, O.V. Borshchev, D.Y. Paraschuk, M.A. Shcherbina, S.N. Chvalun, S.A. Ponomarenko. Proc. SPIE 9568, 95680Z (2015).

[8] O.V. Borshchev, A.S. Sizov, E.V. Agina, A.A. Bessonov, S.A. Ponomarenko. Chem. Commun. 53, 885 (2017).

[9] I.B. Olenych, O.I. Aksimentyeva, L.S. Monastyrskii, O.S. Dzendzeliuk. Mol. Cryst. Liq. Cryst. 640, 165 (2016).

[10] A.N. Aleshin, I.P. Shcherbakov, A.S. Komolov, V.N. Petrov, I.N. Trapeznikova. Org. Electr. 16, 186 (2015).

[11] M. Halik, H. Klauk, U. Zschieschang, G. Schmid, S. Ponomarenko, S. Kirchmeyer, W. Weber. Adv. Mater. 15, 917 (2003).

[12] П.С.Крылов, А.С. Берестенников, С.А. Фефелов, А.С. Комолов, А.Н. Алешин. ФТТ 58, 2476 (2016).

[13] S. Braun, W. Salaneck, M. Fahlman. Adv. Mater. 21, 1450 (2009).

[14] L. Grzadziel, M. Krzywiecki, G. Genchev, A. Erbe. Synth. Met. 223, 199 (2017). 
[15] A.S. Komolov, P.J. Møller, Y.G. Aliaev, S.N. Akhremtchik, K. Schaumburg. J. Mol. Struct. 744-747, 145 (2005).

[16] Д.А. Пудиков, Е.В. Жижин, А.Г. Рыбкин, А.А. Рыбкина, Ю.М. Жуков, О.Ю. Вилков, А.М. Шикин. ФТТ 58, 2459 (2016).

[17] A.S. Komolov, E.F. Lazneva, S.N. Akhremtchik, N.S. Chepilko, A.A. Gavrikov. J. Phys. Chem. C 117, 24, 12633 (2013).

[18] Е.Ю. Афанасьева, Е.В. Рутьков, Н.Р. Галль. ФТТ 58, 7, 1413 (2016).

[19] В.И. Альмяшев, К.Г. Гареев, С.А. Ионин, В.С. Левицкий, B.А. Мошников, Е.И. Теруков. ФТТ 56, 11, 2086 (2014).

[20] A.S. Komolov, P.J. Moeller. Appl. Surf. Sci. 244, 573 (2005).

[21] A.S. Komolov, Y.M. Zhukov, E.F. Lazneva, A.N. Aleshin, S.A. Pshenichnuk, N.B. Gerasimova, Yu.A. Panina, G.D. Zashikhin, A.V. Baramygin. Mater. Des. 113, 319 (2017).

[22] J.F. Moulder, W.F. Stickle, P.E. Sobol, K. Bomben. Handbook of X-ray Photoelectron Spectroscope. 2nd ed./ Ed. J. Chastain. Perkin-Elmer Corporation (Physical Electronics), Eden Prarie. (1992).

[23] A.S. Komolov, K. Schaumburg, P.J. Møller, V.V. Monakhov. Appl. Surf. Sci. 142, 591 (1999).

[24] T.R. Dillingham, D.M. Cornelison, S.W. Townsend. J. Vac. Sci. Technol. A 14, 1494 (1996).

[25] L. Grzadziel, M. Krzywiecki. Synth. Met. 210, 141 (2015).

[26] M.C. Petty Characterization and properties. In: LB Films/ Ed. G. Roberts. Plenum Press, New York (1990). P. 133-222. 